\title{
Generation of THz radiation by photoconductive antennas on based thin films InGaAs and InGaAs/InAlAs.
}

\author{
A.A. Leontyev $^{1}$, K.A. Kuznetsov ${ }^{1}$, G.B. Galiev ${ }^{2}$, G.Kh. Kitaeva ${ }^{1}$, V.V. Kornienko ${ }^{1}$, E.A. \\ Klimov ${ }^{2}$, A.N. Klochkov ${ }^{2}$, S.S. Pushkarev ${ }^{2}$, and P.P. Maltsev ${ }^{2}$ \\ ${ }^{1}$ Lomonosov Moscow State University, Moscow 119991, Russia, aa.leontjev@physics.msu.ru \\ ${ }^{2}$ Institute of Ultrahigh Frequency Semiconductor Electronics, RAS, Moscow 117105, Russia
}

Epitaxial low-temperature grown (LT) semiconductor arsenides (Al, Ga, In)As are widely used as materials for photoconductive antennas (PCA) generators and detectors of pulsed radiation in the terahertz $(\mathrm{THz})$ frequency range [1-3]. It is the combination of subpicosecond carrier lifetime, relatively high mobility and high resistivity that makes LTmaterials suitable for PCA applications. Lately, InGaAs has been investigated as a potential candidate for THz-PCA photoconductive material due to roomtemperature band gap of $0.74 \mathrm{eV}$, which allows for $1.56 \mu \mathrm{m}$ optical excitation with $\mathrm{Er}^{3+}$ fiber laser femtosecond pulses [4-6].

The low substrate temperatures result in a nonstoichiometric growth with the incorporation of excess arsenic in the crystal structure. The most common non-stoichiometry-related point defects in LTarsenides are arsenic antisites with concentrations in the range $10^{17}-10^{19} \mathrm{~cm}^{-3}$ depending on the substrate temperature and arsenic overpressure [7-10]. Antisiterelated defect band in the semiconductor energy bandgap play a significant role in carrier dynamics. Fast non-radiative recombination of photogenerated electrons and holes through antisite centers results in sub-picosecond carrier lifetimes in LT-materials at optimized growth and annealing conditions [11, 12]. It is generally agreed that main traps of photo-excited electrons are ionized antisite defects [13-15].

A possible approach to increase the resistivity of LT-InGaAs structures is to employ LTInGaAs/InAlAs superlattices $[6,13,16,17]$. LT-InAlAs layers have a higher dark resistivity as compared to LT-InGaAs and exhibit deep trap states that are situated energetically below the antisite defect levels of adjacent InGaAs layers that results in a reduction of residual carrier concentration.

The Fig. 1 shows the amplitude of $\mathrm{THz}$ radiation in time domain. It is seen that the signal from an InGaAs /InAlAs-based structure is 5-6 times higher due to a higher bias voltage, which is possible (without sample breakdown) due to higher sample resistance and lower dark current.

Fig. 2 shows a comparison of the Fourier amplitude according to the materials of the antennas LTInGaAs/InAlAs and LT-InGaAs. It is seen that the spectrum of the LT-InGaAs / InAlAs sample is slightly wider in the range from $0.1 \mathrm{THz}$ to $0.6 \mathrm{THz}$ than that of the LT-InGaAs sample. We explain this effect by the difference between the characteristic relaxation times of electrons in the transition from the conduction band to the antisites.

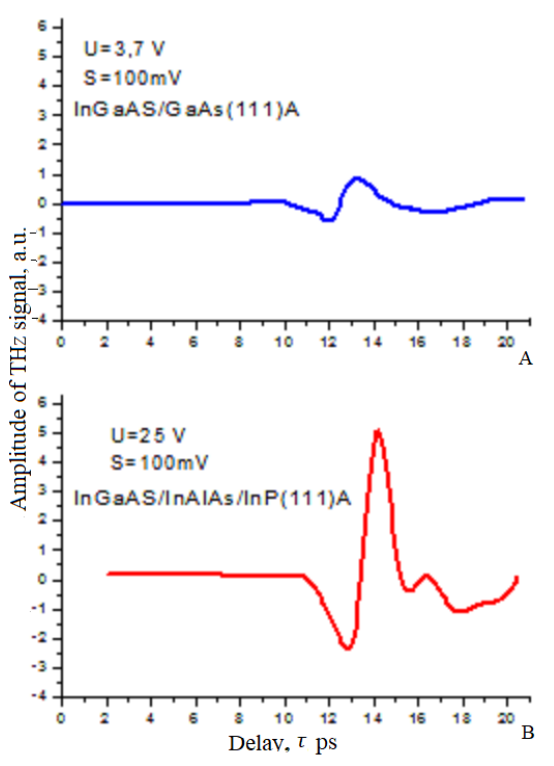

Fig.1. Time-domain waveforms detected for the following antenna materials: A) LT-InGaAs B) LT-InGaAs/InAlAs.

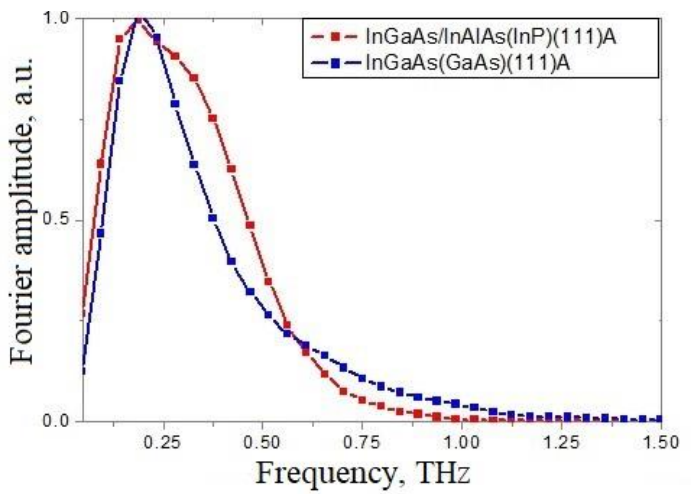

Fig. 2. Compare spectral amplitudes by antenna materials LT-InGaAs(Blue line), LT-InGaAs/InAlAs (Red line).

We determined the characteristic times of electron relaxation by the "pump-probe" spectroscopy method. Fig. 3 shows the dependence of the normalized transmission in time domain for the samples of LT-InGaAs and LT-InGaAs / InAlAs.We used 2-exponentional model for description experimental curves. On figures $\tau_{1}$ is an electron capture time (capture by charge $\mathrm{As}_{\mathrm{Ga}}$ defects) $[18,19], \tau_{2}$ is a recombination time of captured electrons and holes [17]. 


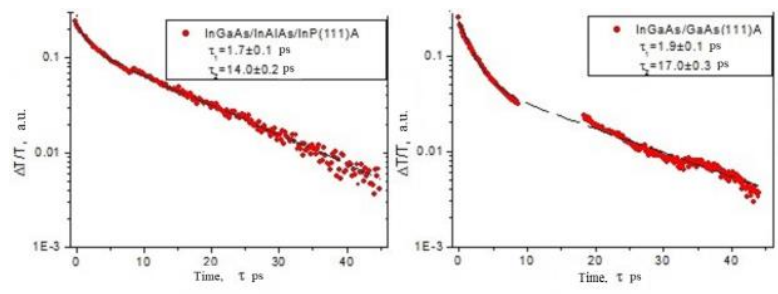

Fig. 3 Change the transmission coefficient in the time domain.

Due to the experimental fact that the characteristic relaxation times for the LT-InGaAs / InAlAs sample are less than for the LT-InGaAs, we observed the difference in the spectra for these samples.

Summing up, it was found that $\mathrm{THz}$ generation is about 5-6 times more efficient in the case of LTInGaAs/InAlAs superlattice than LT-InGaAs generation. It is found that due to the shorter electron relaxation time in the superlattice, the spectrum of these samples is wider in the range of $0.1-0.6 \mathrm{THz}$.

This study was performed under the support of the RFBR grant № 16-02-258a.

\section{References}

1. G.Kh. Kitaev.a Terahertz generation by means of optical lasers // Laser Phys. Lett. V. 559, P. 20085.

2. N.M. Burford and M.O. El-Shenawee. Review of terahertz photoconductive antenna technology // Opt. Eng. 2017, V. 56, P. 10901.

3. E. Castro-Camus and M. Alfaro. Photoconductive devices for terahertz pulsed spectroscopy: a review // Photon. Res. 2016, V. 4, P. A35.

4. A. Takazato M. Kamakura, T. Matsui,J. Kitagawa and $Y$. Kadoya. Terahertz wave emission and detection using photoconductive antennas made on low-temperature-grown InGaAs with $1.56 \mu \mathrm{m}$ pulse excitation // Appl. Phys.Lett. 2007, V. 91, P. 011102.

5. I. Kostakis and M. Missous. Optimization and temperature dependence characteristics of low temperature $\operatorname{In}_{0.3} \mathrm{Ga}_{0.7} \mathrm{As}$ and $\mathrm{In}_{0.53}$ $\mathrm{Ga}_{0.47} \mathrm{AsIn}_{0.52} \mathrm{Al}_{0.48} \mathrm{As}$ semiconductor terahertz photoconductors // AIP Adv. 2013. V. 3, P. 092131.

6. B. Sartorius, H. Roehle, H. Künzel, J. Böttcher, M. Schlak, D. Stanze, H. Venghaus and M. Schell. All-fiber terahertz time-domain spectrometer operating at $1.5 \mu \mathrm{m}$ telecom wavelengths Opt. Express 2008, 169565

7. X. Liu, A. Prasad, J. Nishio, E.R. Weber, Z. Liliental-Weber and W. Walukiewicz. Native point defects in low-temperature-grown GaAs // Appl. Phys. Lett. 1995. V. 67, P. 279.

8. H. Künzel, J. Böttcher, R. Gibis and G. Urmann Material properties of $\mathrm{Ga}_{0.47} \mathrm{In}_{0.53} \mathrm{As}$ grown on $\mathrm{InP}$ by low-temperature molecular beam epitaxy // Appl. Phys. Lett. 1992. V. 61, P. 1347.

9. R.A. Metzger, A.S. Brown, L.G. McCray and H.A Henige. Structural and electrical properties of low temperature GaInAs // J. Vac. Sci. Tech. B. 1993. V. 11, P. 798.

10. M.R. Melloch, J.M. Woodall, E.S. Harmon, N. Otsuka, F.H. Pollak, D.D. Nolte, R.M. Feenstra and M.A. Lutz. Low-temperature grown III-V materials // Annu. Rev. Mater. Sci. 1995. V. 25, P. 547.

11. C. Baker, I.S. Gregory, W.R. Tribe, I.V. Bradley, M.J. Evans, E.H. Linfield and M. Missous. Highly resistive annealed low-temperature-grown InGaAs with sub-500fs carrier lifetimes // Appl. Phys. Lett. 2004. V. 85, P. 4965.

12. K.A. McIntosh, K.B. Nichols, S. Verghese and E.R. Brown. Optical and terahertz power limits in the low-temperature-grown GaAs photomixers // Appl. Phys. Lett. 1997, V. 70, P. 354.

13. B. Globisch, R.J.B. Dietz, D. Stanze, T. Göbel and M. Schell. Carrier dynamics in beryllium doped low-temper-ature-grown InGaAs/InAlAs // Appl. Phys. Lett. 2014. V. 104, P. 172103.

14. Z. Liliental-Weber, H.J. Cheng, S. Gupta, J. Whitaker, K. Nichols and F.W. Smith. Structure and carrier lifetime in LT-GaAs // J. Electron. Mater. 1993. V. 22, P. 1465.

15. U. Siegner, R. Fluck, G. Zhang and U. Keller. Ultrafast high-intensity nonlinear absorption dynamics in low-temperature grown gallium arsenide // Appl. Phys. Lett. 1996. V. 69, P. 2566.

16. H. Kuenzel, K. Biermann, D. Nickel and T. Elsaesser. Low-temperature MBE growth and characteristics of InP-basedAlInAs/GaInAs MQW structures // J. Cryst. Growth. 2001. V. 284, P. 227

17. R.J.B. Dietz, B. Globisch, H. Roehle, D. Stanze, T. Göbel and M. Schell. Influence and adjustment of carrier lifetimesin InGaAs/InAlAs photoconductive pulsed terahertz detectors: $6 \mathrm{THz}$ bandwidth and $90 \mathrm{~dB}$ dynamic range // Opt.Express. 2014. V. 22, P. 19411

18. C. Baker, I.S. Gregory, W.R. Tribe, I.V. Bradley, M.J. Evans, E.H. Linfield and M. Missious. Highly resistive annealed low-temperature-grown InGaAs with sub-500 fs carrier lifetimes // Appl. Phys. Lett. 2004, V. 85, P. 4965.

19. B. Globisch, R. Dietz, R. Kohlhaas, T. Göbel, M. Schell, D. Alcer, M. Semtsiv, and W. Masselink. Iron doped InGaAs: Competitive $\mathrm{THz}$ emitters and detectors fabricated from same photoconductor. // J. Appl. Phys. 2017. V. 121, P. 053102. 